\title{
Identifying Molecular Aetiology of Syndromic and Non syndromic Renal Disorders using Exome Analysis
}

\author{
Aruna Priya \\ Kamineni Academy of https://orcid.org/0000-0001-9313-8102 \\ Santosh Kumar \\ Kamineni Hospitals \\ Gayatri R lyer \\ Kamineni Hospitals https://orcid.org/0000-0003-4811-6750 \\ Qurratulain Hasan ( $\sim$ qhasan2000@yahoo.com ) \\ Kamineni Hospitals https://orcid.org/0000-0002-6162-6379
}

\section{Research Article}

Keywords: Renal disorders, Next Generation Sequencing, Exome analysis, Genetic counseling, prenatal testing

Posted Date: February 14th, 2022

DOI: https://doi.org/10.21203/rs.3.rs-1313278/v1

License: (c) (i) This work is licensed under a Creative Commons Attribution 4.0 International License. Read Full License 


\section{Abstract}

Aim: Renal disorders (RDs) are heterogeneous in nature with different ages of onset ranging from in-utero to adults that arise as independent disease and also as syndromes. RDs are of both heritable and acquired type. The aim of this study was to utilize Next Generation Sequencing to identify the molecular basis of syndromic and non syndromic RDs for management and preventative counselling.

Methods: In the present study cases of RDs which were identified as a solitary health issue and those which had renal disease as part of syndromic features were offered exome analysis by Next Generation Sequencing (NGS) followed by a specific gene panel evaluation after informed consent.

Results: In our study twenty cases were evaluated by NGS based panel tests, a genetic variant was identified in 95\% (19/20) of the cases which could be correlated with the renal phenotype. Based on the American College of Medical Genetics and Genomics $(A C M G)$ guidelines $89 \%(17 / 19)$ of the cases were reported with a Pathogenic or likely pathogenic variant and $10 \%(2 / 19)$ with a Variant of uncertain significance. As expected 8/9 cases with features of polycystic Kidney disease and all eleven cases with syndromic RD had a variant which correlated with phenotype.

Discussion \& Conclusion: NGS enables molecular diagnosis of RD without subjecting patients to invasive tests like renal biopsy as early as the fetal stage. The management and prevention of disease in the family through appropriate genetic counseling is an added advantage.

\section{Introduction}

In recent years the prevalence of Renal disorders (RDs) has been increasing irrespective of age and gender. The population prevalence of kidney disease is more than $10 \%$, and it is more than $50 \%$ in high-risk subpopulations which include hypertensives and diabetics. There are more than 110 genes associated with monogenic diseases with a renal phenotype, autosomal dominant polycystic kidney disease (ADPKD) being the most frequent [Eckardt et al., 2013]. The characterization of kidney disease based on clinical and kidney biopsy features does not provide information of exact etiology due to overlapping symptoms leading to protocol- based treatment [Geara et al., 2019]. The knowledge obtained from the human genome and the advent of high-throughput Next Generation Sequencing (NGS) technology have contributed immensely to identifying the molecular basis of RDs, planning specific management and, providing appropriate genetic counseling to patients and families for prevention.

Vivante [Vivante and Hildebrandt., 2016] stated that End-Stage Renal Disease (ESRD) which appears in the first 25 years of life is largely due to Congenital Anomalies or malfunctioning of the Kidneys and Urinary Tract (CAKUT) and may have a strong genetic basis. Steroid-Resistant Nephrotic Syndrome (SRNS), and Renal Cystic Ciliopathies, which have a genic association develop at different stages of life and are together responsible for nearly $73 \%$ of RDs.

In the present study, we have selected 20 out of 50 patients after genetic counseling, who had clinical/radiological symptoms of RD, had a family history of kidney-related disorders, or had syndromic features including renal issues for NGS followed by a renal panel analysis. This was to help clinicians and patients/families to arrive at a diagnosis to appropriately manage the disorder, and take decisions about renal transplant, reproductive planning and predictive testing with appropriate post-test counseling.

\section{Materials And Methods}

Fifty families were referred from the Nephrology department during the period, 2014 to 2019 with either early age of onset or family history of RDs, for genetic counseling and molecular investigations to the Department of Genetics and Molecular Medicine, of a tertiary care hospital from a cosmopolitan city of South India. Nine of them had a clinical/ radiological diagnosis of ADPKD and eleven had syndromic characteristics including renal disease. Consent for genetic testing after pre-test genetic counseling was obtained from all nineteen patients/families. This study was carried out in accordance with the recommendations of the International Council of Harmonisation and Good Clinical Practice. All subjects/families gave written informed consent in accordance with the Declaration of Helsinki for using their information for research and publication.

\section{Sample collection and Sequence Analysis:}

About $2 \mathrm{ml}$ of peripheral blood was obtained from the affected individual in EDTA vacutainer, and $300 \mu \mathrm{l}$ aliquots of the sample was collected for DNA isolation, rest was sent for commercial clinical exome panel testing to different companies. DNA libraries were prepared from the collected blood samples and sequenced to a mean >80-100x coverage on the lllumina platform. The sequences were then aligned to the human reference genome (GRCh37/hg19) and analyzed to identify the variants relevant to the clinical phenotype [Li and Durbin, 2010; Meyer 
et al., 2013]. Specific variants were reported, after genotype-phenotype correlation and PCR followed by sanger sequencing were carried out by the method described earlier (lyer et al., 2021).

\section{Results}

The age of individuals included in the study ranged from fetus to 46 years, with different types of diagnosis. Of the twenty patients included in the study, eight cases (table1 \& 2) had a family history of the same or similar disorder, while the remaining were apparently sporadic cases.

Molecular testing of nine cases with radiological features of PKD had a variant in PKD1 or PKD2, diagnostic of autosomal dominant Polycystic Kidney Disease (ADPKD, while one case exhibited autosomal recessive PKD with a homozygous pathogenic variant in PKHD1 gene. Hence, the diagnostic yield was $8 / 9$ (88.88\%) with only one individual where a causative gene variant was not identified indicating either a larger panel of clinical-exome or whole-exome test may be required for this individual (Table 1).

Of the eight cases of PKD, NGS testing identified heterozygous pathogenic or likely pathogenic variants in PKD1 or PKD2 in five cases and PKHD1 in one case. Two cases (1.2 \&1.7 in table1) had a VUS which requires further functional assessment for appropriate genetic counseling. Case 1.2 was a fetus diagnosed with PKD during routine antenatal ultrasound screening and the couple opted for termination and testing. The VUS identified was evaluated in parents by targeted sanger sequencing. Father had the same variant and was referred to Nephrology and Radiology departments for evaluation before planning subsequent pregnancies.

The eleven cases with syndromic RD had a molecular diagnosis of Alport Syndrome in three cases, Bardet-Biedl Syndrome in five cases and one case each of Renal tubular acidosis with sensorineural deafness X linked dominant phosphatemic Rickets and Nephrogenic Diabetes incipidus (Table 2).

Two individuals from PKD group were born to consanguineous couples (Table 1), while in cases of syndromic RD 6/11 individuals had consanguinity (Table 2). All the syndromic RD cases with consanguinity and two cases with non -consanguinity harbored homozygous variants. There were three cases with X-linked variants among syndromic RD cases (Table 2).

Table 1.0

Clinically and radiologically diagnosed PKD cases with molecular findings

\begin{tabular}{|c|c|c|c|c|c|c|c|}
\hline S.No & AGE & SEX & $\begin{array}{l}\text { CONSANGUINITY IN } \\
\text { PARENTS }\end{array}$ & $\begin{array}{l}\text { FAMILY } \\
\text { HISTORY }\end{array}$ & ZYGOSITY & VARIATION & SIGNIFICANCE \\
\hline 1.1 & 23 & $\mathrm{~F}$ & No & Yes & Heterozygous & $\begin{array}{l}\text { PKD1 intron } 26 \text { c.9398-2 } \\
A>G \\
\text { 3'splice variant }\end{array}$ & Pathogenic \\
\hline 1.2 & Foetus & $\mathrm{F}$ & Yes & Yes & Heterozygous & $\begin{array}{l}\text { PKD2 exon } 6 \text { c. } 1505 \text { A>G } \\
\text { P.Tyr502Cys }\end{array}$ & VUS \\
\hline 1.3 & 21 & M & Yes & No & Heterozygous & $\begin{array}{l}\text { PKD2 exon } 2 \text { c.637C>T } \\
\text { p.Arg } 213 X\end{array}$ & Pathogenic \\
\hline 1.4 & 22 & $\mathrm{~F}$ & No & Yes & Heterozygous & $\begin{array}{l}\text { PKD1 exon23 c.8325delG } \\
\text { p.Leu2776Trpfs99X }\end{array}$ & Likely pathogenic \\
\hline 1.5 & 34 & $\mathrm{~F}$ & No & No & Heterozygous & $\begin{array}{l}\text { PKD1 exon43 } \\
\text { c.11944C>T }\end{array}$ & Pathogenic \\
\hline 1.6 & 27 & $\mathrm{~F}$ & No & No & Heterozygous & $\begin{array}{l}\text { PKHD1 c. } 10392 \text { del C } \\
\text { p.lle3465SerfsTer46 }\end{array}$ & Likely Pathogenic \\
\hline 1.7 & 46 & $\mathrm{~F}$ & No & No & Heterozygous & $\begin{array}{l}\text { PKD1 exon } 18 \text { c.7409C>T } \\
\text { p.Pro2470Leu }\end{array}$ & VUS \\
\hline 1.8 & 46 & $\mathrm{~F}$ & No & & Heterozygous & $\begin{array}{l}\text { PKD1 } \\
\text { Exon11c.2638_2657dup } \\
\text { p.Trp887Pro fsTer } \\
18\end{array}$ & Likely pathogenic \\
\hline 1.9 & 34 & M & No & No & - & - & $\begin{array}{l}\text { No variation } \\
\text { detected }\end{array}$ \\
\hline
\end{tabular}


Note: PKD1- Polycystin 1, Transient Receptor Potential Channel Interacting; PKD2-Polycystin 2, Transient Receptor Potential Cation Channe, PKHD1- PKHD1 Ciliary IPT Domain Containing Fibrocystin/ Polyductin.

Table 2.0

LIST OF SYNDROMIC CASES WITH RENAL INVOLVEMENT

\begin{tabular}{|c|c|c|c|c|c|c|c|c|}
\hline S.No & AGE & SEX & $\begin{array}{l}\text { CONSANGUINITY } \\
\text { IN PARENTS }\end{array}$ & $\begin{array}{l}\text { FAMILY } \\
\text { HISTORY }\end{array}$ & ZYGOSITY & VARIATION & $\begin{array}{l}\text { DISEASE } \\
\text { CAUSED }\end{array}$ & SIGNIFICANCE \\
\hline 2.1 & 17 & $M$ & No & Yes & Homozygous & $\begin{array}{l}\text { COL4A3 exon37 } \\
\text { c.3109C>T } \\
\text { p.Arg1037X }\end{array}$ & Alport syndrome & Pathogenic \\
\hline 2.2 & 27 & $\mathrm{~F}$ & Yes & No & Homozygous & $\begin{array}{l}\text { COL } 4 A 3 \text { exon } 47 \\
\text { c.4235G>T } \\
\text { p.Gly } 1412 \mathrm{Val}\end{array}$ & Alport syndrome & Pathogenic \\
\hline 2.3 & 23 & $\mathrm{~F}$ & No & No & Heterozygous & $\begin{array}{l}\text { COL4A5 exon19 } \\
\text { c.1117C>T } \\
\text { p.Arg373X }\end{array}$ & Alport syndrome & Pathogenic \\
\hline 2.4 & 10 & $\mathrm{~F}$ & Yes & No & Homozygous & $\begin{array}{l}\text { BBS9 exon3 } \\
\text { c.238C>T } \\
\text { p.GIn80X }\end{array}$ & $\begin{array}{l}\text { Bardet-Biedl } \\
\text { syndrome }\end{array}$ & Pathogenic \\
\hline 2.5 & $\begin{array}{l}07 \\
\text { Months }\end{array}$ & $M$ & Yes & No & Homozygous & $\begin{array}{l}\text { BBS10 exon2 } \\
\text { c.1335-1338 del } \\
\text { p.Tyr448Argfs } \\
\text { Ter39 }\end{array}$ & $\begin{array}{l}\text { Bardet-Biedl } \\
\text { syndrome }\end{array}$ & Pathogenic \\
\hline 2.6 & 16 & M & Yes & Yes & Homozygous & $\begin{array}{l}\text { BBS10 exon } 1 \\
\text { c. } 146 \mathrm{G}>\mathrm{T} \\
\text { p.Arg49Leu }\end{array}$ & $\begin{array}{l}\text { Bardet-Biedl } \\
\text { syndrome }\end{array}$ & $\begin{array}{l}\text { Likely } \\
\text { Pathogenic }\end{array}$ \\
\hline 2.7 & Fetus & & No & No & Homozygous & $\begin{array}{l}\text { BBS10 exon2 } \\
\text { c.271dupT } \\
\text { P. Cys91LeufsTer5 }\end{array}$ & $\begin{array}{l}\text { Bardet-Biedl } \\
\text { syndrome }\end{array}$ & Pathogenic \\
\hline 2.8 & 17 & $\mathrm{~F}$ & Yes & No & Homozygous & $\begin{array}{l}\text { BBS10 exon2 } \\
\text { C.1599_1603 } \\
\text { delinsG } \\
\text { P. Thr534lle fs21 }\end{array}$ & $\begin{array}{l}\text { Bardet-Biedl } \\
\text { syndrome }\end{array}$ & Pathogenic \\
\hline 2.9 & 08 & $M$ & Yes & Yes & Homozygous & $\begin{array}{l}\text { ATP6V1B1 exon } 10 \\
\text { c.925G>T } \\
\text { p.Glu309Ter }\end{array}$ & $\begin{array}{l}\text { Renal Tubular } \\
\text { Acidosis with } \\
\text { deafness }\end{array}$ & $\begin{array}{l}\text { Likely } \\
\text { pathogenic }\end{array}$ \\
\hline 2.10 & 31 & $\mathrm{~F}$ & No & Yes & Heterozygous & $\begin{array}{l}\text { PHEX exon } 15 \\
\text { c. } 1601 \mathrm{C}>\mathrm{T} \\
\text { p.Pro534Leu }\end{array}$ & $\begin{array}{l}\text { Hereditary } \\
\text { Hypophosphatemic } \\
\text { Rickets }\end{array}$ & Pathogenic \\
\hline 2.11 & 21 & M & No & No & Hemizygous & $\begin{array}{l}\text { AVPR2 Exon } 2 \\
\text { C.553del } \\
\text { p.Gly185ValfsTer27 }\end{array}$ & $\begin{array}{l}\text { Nephrogenic } \\
\text { diabetes insipidus }\end{array}$ & Pathogenic \\
\hline
\end{tabular}

COL4A3- Collagen type IV alpha 3 chain; COL4A5- Collagen type IV alpha 5 chain; BBS9-Bardet-Biedl syndrome 9; BBS10- Bardet-Biedl syndrome 10; ATP6V1B1- ATPase H+ transporting V1 subunit B1; PHEX- Phosphate regulating Endopeptidase homolog X-linked; AVPR2Arginine Vasopressin Receptor 2.

\section{Discussion}


Diagnosis and management of RDs until recently relied on the assessment of the primary physician along with biochemical, radiological, and pathological tests. The overlapping spectrum of manifestations was the major reason for the limitations in the exact clinical diagnosis of renal diseases [Mansilla et al., 2019]. Molecular diagnosis of inherited kidney diseases remains a challenge due to their expanding phenotypic spectra, as well as, the constantly growing list of disease-causing genes [Bullich., 2018]. According to Jha et al end-stage renal disease (ESRD), is an increasing public health issue with an estimated prevalence of 8-16\% worldwide [Jha., 2013]. According to Mele et al [Mele et al., 2011] ESRD necessitates dialysis or transplantation for survival and is a cause of morbidity and mortality. Hence, knowing the underlying genetic cause of RD will help in planning novel therapies and strategies for treatment /management and prevention.

The rapid changes in the methodology of genetic testing, especially NGS have become important to identify causative disease genes, which will facilitate the use of molecular diagnosis and reduce the need for invasive diagnostic procedures, such as renal biopsy [Bullich et al., 2018]. In our present study, twenty cases were evaluated by NGS-based panel tests, and phenotype-associated gene variants were identified in nineteen cases. This high diagnostic yield of $95 \%$ was achieved because the cases were selected for exome testing after genetic counseling which included pedigree analysis and syndrome identification based on clinical, radiological, and family details.

The patients included in the present study were clinically categorized into two groups: Polycystic Kidney Disease (PKD) and Syndromic cases with renal involvement.

\section{POLYCYSTIC KIDNEY DISEASE (PKD)}

PKD is an inherited disorder in which clusters of non-cancerous water-like fluid-filled sacs develop that interfere with the ability of the kidney to filter waste. The most common form of PKD is Autosomal dominant PKD (ADPKD), which is the adult onset and Autosomal recessive PKD (ARPKD) is the neonatal form of PKD. ADPKD is caused by mutations in PKD1 and PKD2 genes that code for two different proteins called Polycystin 1 and Polycystin 2 respectively. They work together for the normal functioning of the kidney. ARPKD phenotype is variable and is caused by mutations in Polycystic Kidney and Hepatic Disease 1 (PKHD1) gene that codes for fibrocystin protein, a cliliary protein spanning kidney cell membrane and has also been associated with PKD [Harris and Torres., 2009]. Damaging sequence variations in these genes lead to dysfunction of proteins resulting in numerous progressively enlarging cysts in the kidneys, leading to structural damage and loss of function progressively causing end-stage renal disease. From our study PKD cases had a very high molecular diagnostic rate with five cases with PKD1, two cases with PKD2, and one case with PKHD1 variants. This is similar to what was reported by Groopman who demonstrated maximum variants from PKD1 and PKD2 genes from samples of kidney diseases[Groopman et al., 2019].

According to the American College of Medical Genetics and Genomics (ACMG) guidelines, $17 / 19$ (89\%) of the cases from the current study were reported with a pathogenic or likely pathogenic variant. In a study by Mansilla et al., 2019, NGS based genetic testing on patients with various renal phenotypes had identified $43 \%$ of variants to be pathogenic and likely pathogenic. In the present study two VUS were identified: (i) Case 1.2, which was a fetus, with PKD2 exon 6 c.1505 A>G p.Tyr502Cys variant. Segregation analysis of parents revealed that the father had the same variant and he was referred to radiology and nephrology surveillance prior to prenatal evaluation. (ii) Case 1.7 , a 46 year old female with no family history of PKD was identified with PKD1 exon 18 c.7409C>T p.Pro2470Leu.She was counselled for targeted segregation analysis in the family to identify if this was a denovo variant.

\section{SYNDROMIC CASES WITH RENAL INVOLVEMENT}

There ar several syndromes in which abnormalities in the renal system are observed. Eleven syndromic cases after genetic counselling were offered NGS testing which was able to provide a diagnosis to all the cases.

Three cases clinically diagnosed with progressive loss of kidney function were identified with pathogenic variants in COL4 genes associated with Alport syndrome (AS), two of them (2.1 \& 2.2) had homozygous COL4A3 pathogenic variants indicating autosomal recessive inheritance and one case (2.3) had a X linked heterozygous COL4A5 variant associated with X linked dominant inheritance (Table2). AS is a hereditary disease caused by mutations in collagen type IV alpha chain genes (COL4A3/ COL4A4/ COL4A5, OMIM: 12007, 120131, 303630). The progressive damage to the basement membrane with mutated form of type 4 collagen leads to microscopic hematuria, sensorineural deafness, anterior lenticonus, and progressive kidney dysfunction leading to end-stage renal disease [Kashtan and Michael., 1996]. Girimaji reported an autosomal recessive pathogenic novel variant c. $1891 \mathrm{G}>\mathrm{A}$ in exon 26 of COL4A3 gene leading to end stage renal disease from an Indian patient born to a consanguineous couple [Girimaji et al., 2020].

Four patients and one fetus were seen with homozygous pathogenic/likely pathogenic variants in genes associated with Bardet Biedl syndrome. Of the five cases, one case (2.4) had a homozygous pathogenic variant in BBS9 gene, and the remaining had variants in BBS10 gene (Table2). Segregation analysis in parents was performed in case 2.7 and 2.8, showing that both parents were carriers for the reported variant and this information could be used for subsequent prenatal diagnosis. 
BBS is an autosomal recessive disorder was identified is a ciliopathy disorder, affecting vision, intelligence, genitalia renal function and also show polydactyly, however, variable expression and heterogeneity of features is seen (Priya et al ., 2016). Although globally BBS1 is considered to be the most common type, however, an earlier report from India by Chandrasekhar et al (2018) also showed BBS10 to be most common in India. A founder mutation, $\mathrm{C} 91 \mathrm{fs} * 95$ was also found in a fetal sample identified to have polycystic kidneys in prenatal ultrasound of a nonconsanguineous couple with a history of previous terminated pregnancy with the similar renal features. Segregation analysis of the couple revealed them to be carriers. This founder mutation has also been reported in other studies from India, Chandrasekhar et al (2018).

A child experiencing dehydration, nausea, poor weight gain, rickets with kidney stones was identified with a homozygous likely pathogenic variant in the ATP6V1B1 gene, which impairs the function of the V-ATPase proton pump resulting in the loss of control on pH of the fluid in the inner ear leading to sensorineural hearing loss and loss of control on acidity of the blood leading to demineralization of bones and other consequences of metabolic acidosis, which Is characterized by hyperchloremic metabolic acidosis, hypokalemia, hypercalciuria, hypocitraturia, nephrocalcinosis, and conserved glomerular filtration rate. [Escobar et al., 2016]. Sethi reported a pathogenic variant in exon 1 of ATP6V1B1 in an Indian family with distal RTA and sensorineural deafness [Sethi., et al 2009].

The Segregation analysis in parents of case 2.9 revealed them to be carriers. The couple was counseled that the recurrence risk is $25 \%$ for all subsequent pregnancies and were explained about using this variant for prenatal diagnosis.

Two cases were identified with $X$ linked gene variants. One was X-linked hypophosphataemia (XLH) and the other was Hemizygous Nephrogenic Diabetes incipidus (Table 2): i) Mutations in Phosphate-regulating Endopeptidase Homolog X-linked (PHEX) gene cause hypophosphataemia, impaired synthesis of active vitamin $D\left(1,25(\mathrm{OH})_{2}\right.$ vitamin $\left.\mathrm{D}\right)$, rickets, mineralization defect of bones, teeth and disproportionate short stature [10]. PHEX gene encodes a cell-surface-bound protein-cleavage enzyme that is predominantly expressed in osteoblasts, osteocytes and teeth causes renal phosphate wasting. The family in the present study had multiple members effected (figure 1) showed a pathogenic, heterozygous variant in exon 15 of PHEX gene. The degree of severity among the affected members of the family harboring the above mentioned variation was different, suggestive of $X$ linked dominant inheritance with variable expressivity. ii) Nephrogenic Diabetes inipidus (NDI) causes water imbalance due to the inability of the kidney to concentrate urine from the blood stream in response to antidiuretic hormone vasopressin (AVP) leading to large volume of un-concentrated urine (case 2.11) (Ma et al., 2020). 90\% of the NDI cases are due to sequence changes in AVPR2 gene present on the X chromosome, which in X-linked recessive inheritance affects males mainly and the rest $10 \%$ are due to sequence changes in the AQP2 gene variants which result in both autosomal recessive and autosomal dominant inheritance (Fujiwara and Bichet, 2005). In the case included in the study nonsense deletion at 553 position results in premature truncation of the protein at codon 185 leading to NDI. Tayfur et al., 2018 reported a case of NDI in a six year boy with a hemizygous variant in exon 2 of AVPR2 gene resulting in the incorporation of Tyrosine in place of Histidine that ultimately leads to inappropriate protein folding.

In our study 11/50 showed to have a syndromic condition after first round of genetic counselling. All eleven cases had a molecular diagnosis after testing, giving us a very high diagnostic yield. Five of the cases which showed the features of Bardet Biedl syndrome (BBS) were confirmed by molecular diagnosis of BBS with four of them having a pathogenic variant in BBS10 gene and one in BBS9 gene. Three of the cases were diagnosed to have Alport syndrome, of which two had variants in COL4A3 causing autosomal dominant inheritance and one had COL4A5 variant that cause $X$ linked dominant Alport syndrome. All three variants were in exonic region, two were frameshift mutations responsible for protein termination post Arginine truncation. The third variant was a missense variant altering the protein in codon 1412.

According to Liebau and Benzing investigations of rare genetic disorders can serve as a starting point for the development of novel therapeutic strategies in RDs that are inherited [Liebau and Benzing, 2011]. NGS based genetic testing if applied at an early stage of the diagnostic process, reduces the unnecessary financial burden involved in repeated hospital visits and laboratory tests especially in a country like India, where the healthcare is not covered by the governmental schemes for majority of the population.

\section{Conclusion}

NGS enables diagnosis without subjecting patients to invasive tests like renal biopsy at an early stage of disease and indicate specific therapeutic options and improves the management. Adopting broad WES panels has the advantages of evaluating the coding portions of all genes and has the potential to identify variants in the candidate genes that could be involved in RDs. Benefits of this could be achieved with a multidisciplinary approach involving clinicians, best practice of genetic testing and collaboration between medical geneticists and genetic counselors.

\section{Declarations}

Ethics approval and consent to participate: Study was carried out in accordance with the recommendations of International Council of Harmonization and Good Clinical Practice. All subjects/families gave written informed consent in accordance with the Declaration of 
Helsinki

Consent for publication: Not Applicable

Availability of data and materials: Any additional information can be shared upon request

Competing interests: The authors declare there are no competing interests.

Funding: This research did not receive any specific grant from funding agencies in the public, commercial, or not-for-profit sectors

Author's contribution: APK wrote the first draft of the manuscript, SK reviewed and curated the clinical information, GRI compiled patient information and $\mathrm{QH}$ supervised the project and did scientific editing of the manuscript. All authors reviewed the manuscript.

Acknowledgement: Patients and families, Staff, Genetic counselors and students of Department of Genetics \& Molecular Medicine and Department of Nephrology, Kamineni Hospitals.

\section{References}

1. Eckardt KU, Coresh J, Devuyst O, Johnson RJ, Köttgen A, Levey AS, Levin A. Evolving importance of kidney disease: from subspecialty to global health burden. The Lancet. 2013 Jul 13;382(9887):158-69.

2. Geara AS, Kallish S, Hogan JJ. The Impact of Whole-Exome Sequencing on Kidney Disease Ontology: The Tip of the Iceberg?. American Journal of Kidney Diseases. 2019 Aug 1;74(2):281-3.

3. Vivante A, Hildebrandt F. Exploring the genetic basis of early-onset chronic kidney disease. Nature Reviews Nephrology. 2016 Mar;12(3):133.

4. Li, H. and R. Durbin. Fast and accurate long-read alignment with Burrows-Wheeler transform. Bioinformatics, $2010.26(5):$ p. 589-95.

5. Meyer, L.R., et al., The UCSC Genome Browser database: extensions and updates 2013. Nucleic Acids Res, 2013. 41(D1): p. D64-9.

6. Harris PC, Torres VE. Polycystic kidney disease. Annual review of medicine. 2009 Feb 18;60:321-37.

7. Kashtan, C. E., \& Michael, A. F. (1996). Alport syndrome. Kidney International, 50(5), 1445-1463. 10.1038/ki.1996.459

8. Escobar LI, Simian C, Treard C, Hayek D, Salvador C, Guerra N, Matos M, Medeiros M, Enciso S, Camargo MD, Vargas-Poussou R. Mutations in ATP6V1B1 and ATP6V0A4 genes cause recessive distal renal tubular acidosis in Mexican families. Molecular genetics \& genomic medicine. 2016 May;4(3):303-11.

9. Jha V, Garcia-Garcia G, Iseki K, Li Z, Naicker S, Plattner B, Saran R, Wang AY, Yang CW. Chronic kidney disease: global dimension and perspectives. The Lancet. 2013 Jul 20;382(9888):260-72.

10. Mansilla MA, Sompallae RR, Nishimura CJ, Kwitek AE, Kimble MJ, Freese ME, Campbell CA, Smith RJ, Thomas CP. Targeted broad-based genetic testing by next-generation sequencing informs diagnosis and facilitates management in patients with kidney diseases. Nephrology Dialysis Transplantation. 2019 Nov 18.

11. Bullich G, Domingo-Gallego A, Vargas I, Ruiz P, Lorente-Grandoso L, Furlano M, Fraga G, Madrid Á, Ariceta G, Borregán M, Piñero-Fernández JA. A kidney-disease gene panel allows a comprehensive genetic diagnosis of cystic and glomerular inherited kidney diseases. Kidney international. 2018 Aug 1;94(2):363-71.

12. Mele C, latropoulos P, Donadelli R, Calabria A, Maranta R, Cassis P, Buelli S, Tomasoni S, Piras R, Krendel M, Bettoni S. MY01E mutations and childhood familial focal segmental glomerulosclerosis. New England Journal of Medicine. 2011 Jul 28;365(4):295-306.

13. Liebau MC, Benzing T. Recent developments in genetic kidney diseases. Deutsche medizinische Wochenschrift (1946). 2011 May;136(19):1014-20.

14. Groopman EE, Marasa M, Cameron-Christie S, Petrovski S, Aggarwal VS, Milo-Rasouly H, Li Y, Zhang J, Nestor J, Krithivasan P, Lam WY. Diagnostic utility of exome sequencing for kidney disease. New England Journal of Medicine. 2019 Jan 10;380(2):142-51.

15. Sethi SK, Singh N, Gil H, Bagga A. Genetic studies in a family with distal renal tubular acidosis and sensorineural deafness. Indian pediatrics. 2009 May 1;46(5).

16. Girimaji N, Murugan SM S, Nada R, Sharma A, Rathi M, Kohli HS, Gupta KL, Ramachandran R. Successful renal transplantation in a family with a novel mutation in COL4A3 gene and autosomal recessive Alport syndrome. Nephrology. 2020 Jun;25(6):497-501.

17. Fujiwara TM, Bichet DG. Molecular biology of hereditary diabetes insipidus. Journal of the American Society of Nephrology. 2005 Oct 1;16(10):2836-46.

18. Tayfur AÇ, Karaduman T, Türkmen MÖ, Şahin D, Yılmaz AÇ, Büyükkaragöz B, Buluş AD, Mergen H. A novel mutation in the AVPR2 gene causing congenital nephrogenic diabetes insipidus. Journal of clinical research in pediatric endocrinology. 2018 Dec;10(4):350. 
19. Iyer GR, Kumar R, Poornima S, Priya A, Juturu K, Bhatnagar L, Arora S, Suresh V, Utage P, Bailur S, Pujar AN. Utility of Next Generation Sequencing in Genetic Testing and Counseling of Disorders Involving the Musculoskeletal System-Trends Observed From a Single Genetic Unit.

20. Priya S, Nampoothiri S, Sen P, Sripriya S. Bardet-Biedl syndrome: Genetics, molecular pathophysiology, and disease management. Indian journal of ophthalmology. 2016 Sep;64(9):620.

21. Chandrasekar SP, Namboothiri S, Sen P, Sarangapani S. Screening for mutation hotspots in Bardet-Biedl syndrome patients from India. The Indian journal of medical research. 2018 Feb;147(2):177.

22. Ma L, Wu D, Wang X, Yang Y. A Case of Congenital Nephrogenic Diabetes Insipidus Caused by Thr108Met Variant of Aquaporin 2. Frontiers in pediatrics. 2020 Jan 30;8:15.

Figures

\section{Image not available with this version}

\section{Figure 1}

Figure 1 not available with this version. 